\title{
National general practice study of epilepsy: the social and psychological effects of a recent diagnosis of epilepsy
}

\author{
J E Chaplin, R Yepez Lasso, S D Shorvon, M Floyd
}

\begin{abstract}
Objectives-To determine the nature and extent of psychosocial problems in epilepsy and their associations.

Design-A postal survey was used drawing data from prospective consecutive cases. Data on demographic, medical, and social backgrounds were collected. A specially designed, validated attitude questionnaire examined 14 areas of psychosocial adjustment to epilepsy.

Setting-124 primary care general practices.

Subjects-Adults (aged over 17) with a recent diagnosis of epilepsy (within previous 36 months). They were registered with the national general practice study of epilepsy and had a confirmed diagnosis according to the usual criteria. 216 subjects were approached for the survey by their general practitioners; 192 returned questionnaires.

Results-Problems in at least one area were experienced by 175 (91\%) of the 192 subjects. Problems were generally mild, which contrasts strongly with findings in chronic cases. The areas of greatest concern were fear of seizures $(80 \%$ of cases; $72 \%$ moderate or severe) and fear of stigma in employment ( $69 \%$ of cases; $40 \%$ moderate or severe). A highly significant relation was found between psychosocial effects and the frequency and recency of seizures.

Conclusions-In the early stages of epilepsy psychosocial effects are closely related to the severity of the medical condition, suggesting that the argument for the stigmatising effect of the diagnosis by itself is less important than previously thought. The findings also suggest that problems may evolve as the condition becomes chronic.
\end{abstract}

\section{Introduction}

A recent review article stated that a "plethora of studies deal with the importance of psychosocial aspects of epilepsy." Many different aspects of psychosocial adjustment have been considered, and the general conclusion has been that "significant psychosocial problems are frequently found." However, most data concerning the medical and social course of epilepsy come from retrospective studies, usually hospital based clinics in which patients with chronic disease are overrepresented and hence provide unreliable information. ${ }^{3}$

The purpose of this study was, firstly, to identify the nature and extent of psychosocial maladjustment in patients with newly diagnosed epilepsy and, secondly, to investigate the extent to which these problems are caused by either the diagnosis alone-that is, present soon after diagnosis - or the medical condition - that is, the frequency or recency of seizures.

The study was undertaken among recently diagnosed adult patients (diagnosis made within previous 36 months) who were registered with the national general practice study of epilepsy. That study is a population based cohort study of newly diagnosed cases of epilepsy and is the first large scale study from the time of the first epileptic attack. The importance of the national general practice study of epilepsy has been its ability to gather unbiased and comprehensive information on an unselected population based on prospective consecutive cases. The patients were drawn from a base of 275 primary care practices across the United Kingdom, and this was a crucial feature of the design. ${ }^{45}$ The basis for the definition of epilepsy was on clinical grounds and after investigation according to the usual criteria. The general practitioners participating in the study were recruited by personal contact and by advertisement in the medical press covering rural and urban areas from all parts of the United Kingdom. ${ }^{6}$

Pilot work was carried out in a series of in depth interviews with patients with epilepsy attending the epilepsy clinics at the National Hospital for Neurology and Neurosurgery. The interviews were based partly on existing instruments - for example, the Washington psychosocial inventory-but the subjects were also encouraged to talk freely about problems they had encountered. This identified the areas which were specifically relevant to psychosocial adjustment in epilepsy, and on the basis of these interviews a new attitude questionnaire was constructed for use in a postal survey.

Twenty one areas of psychosocial adjustment were originally identified. After a criterion related validity study on 20 subjects using an independent assessment of their behaviour from medical staff closely associated with them ${ }^{7} 14$ areas of psychosocial adjustment were found to be valid and were selected for inclusion in the questionnaire. The average correlation was 0.38 . The areas are summarised as follows: acceptance of the diagnosis (A1), fear of having seizures (A2), fear of stigma affecting employment (A3), lack of confidence about the future (A4), lack of confidence about travelling (A5), adverse effect on social life (A6), adverse effect on leisure pursuits (A7), change of outlook on life or self (A8), difficulty with the family (A9), attitudes to taking medication (A10), attitude to the medical profession (A11), depression or emotional reactions (A12), feeling of increased social isolation (A13), and lack of energy or lethargy (A14).

A reliability study was also carried out utilising a test-retest procedure over one month. The responses from 20 subjects were compared by using a Pearson correlation analysis. The overall correlations were found to be significant and satisfactorily high, indicating good reliability. The average overall reliability level was $0 \cdot 64$.

\section{Method}

The general practitioners taking part in the national general practice study of epilepsy and who agreed to
Correspondence to:

BMF 1992;304:1416-8 
participate in the psychosocial aspect were sent a questionnaire for all adult subjects (aged over 17) with a confirmed diagnosis of epilepsy who were registered with the national study and asked to forward it to those subjects. A total of 124 primary care practices participated and 216 questionnaires were forwarded to subjects. Confidentiality was assured by the questionnaires being numbered and returned direct to the research office. Patients' names were not forwarded to that office. The questionnaire comprised an attitude profile and general questionnaire.

Each subject was asked to judge to what extent he or she was affected in each of the 14 areas. Each area was represented by three statements on a five point scale from always true to never true. The items were based on the statements made by subjects during in depth interviews. Items were weighted for importance by using a paired comparison procedure. ${ }^{78}$ In addition, demographic data were collected, together with data concerning the medical history. The responses to each problem area were then categorised as mild, moderate, or severe based on the weighted scores (1-10, 11-30, 31-40 respectively). These scores were then assessed in relation to demographic data, medical history (total number of seizures or recency of seizures), and social background by using a one way analysis of variance.

No $(\%)$ respondents

\begin{tabular}{lr}
\hline Sex: & \\
Male & $106(55 \cdot 2)$ \\
Female & $86(44 \cdot 8)$ \\
Age (years): & \\
$17-31$ & $73(38 \cdot 0)$ \\
$32-45$ & $37(19 \cdot 3)$ \\
$46-59$ & $24(12 \cdot 5)$ \\
$\geqslant 60$ & $58(30 \cdot 2)$ \\
\end{tabular}

TABLE II -Number of problem areas experienced by each subject

\begin{tabular}{|c|c|c|c|}
\hline \multirow{2}{*}{$\begin{array}{l}\text { No of } \\
\text { problem } \\
\text { areas }\end{array}$} & \multicolumn{2}{|c|}{$\begin{array}{l}\text { Proportion of } \\
\text { subjects } \\
\text { experiencing } \\
\text { problem }\end{array}$} & \multirow[b]{2}{*}{$\begin{array}{l}\text { No of } \\
\text { subjects }\end{array}$} \\
\hline & $\%$ & $\underset{\%}{\text { Cumulative }}$ & \\
\hline 0 & 9 & 100 & 192 \\
\hline$\geqslant 1$ & 5 & 91 & 175 \\
\hline$\geqslant 2$ & 4 & 86 & 166 \\
\hline$\geqslant 3$ & 5 & 82 & 158 \\
\hline$\geqslant 4$ & 7 & 77 & 148 \\
\hline$\geqslant 5$ & 6 & 70 & 134 \\
\hline$\geqslant 6$ & 4 & 64 & 123 \\
\hline$\geqslant 7$ & 10 & 60 & 115 \\
\hline$\geqslant 8$ & 4 & 50 & 96 \\
\hline$\geqslant 9$ & 7 & 46 & 83 \\
\hline$\geqslant 10$ & 7 & 39 & 69 \\
\hline$\geqslant 11$ & 5 & 32 & 60 \\
\hline$\geqslant 12$ & 6 & 27 & 49 \\
\hline$\geqslant 13$ & 6 & 21 & 37 \\
\hline 14 & 15 & 15 & 29 \\
\hline
\end{tabular}

\section{Results}

Results were obtained from 192 subjects (table I), a response rate of $89 \%$. Non-respondents did not differ from respondents in age or sex.

Subjects experienced problems in a varying number of the 14 areas examined: 175 subjects $(91 \%)$ indicated a problem in at least one area, and 29 subjects $(15 \%)$ had problems in all 14 areas (table II).

The severity of the problems experienced and the proportion of people having these problems are shown in table III. Areas causing the most problems were acceptance of the diagnosis, fear of having seizures, and fear of stigma affecting employment. Areas most likely to cause severe problems were fear of having seizures, fear of stigma in employment, adverse effects on leisure pursuits, and lack of energy.

ASSOCIATION WITH INDEPENDENT DEMOGRAPHIC, SOCIAL, AND MEDICAL VARIABLES

No association with the presence or severity of the treated problems was found in relation to the sex of the subject, marital status, or type of job. An overall effect for age was noted, a low number of problems being reported by subjects over 60 . When that age group was removed from the analysis the association was no longer significant.

TABLE III - Percentages of 192 subjects reporting problems in surveyed areas, and their severity

\begin{tabular}{lcccc}
\hline & \multicolumn{4}{c}{ Severity of problem ${ }^{\star}$} \\
\cline { 2 - 5 } & $\begin{array}{c}\text { None } \\
(0)\end{array}$ & $\begin{array}{c}\text { Mild } \\
(1-10)\end{array}$ & $\begin{array}{c}\text { Moderate } \\
(11-30)\end{array}$ & $\begin{array}{c}\text { Severe } \\
(31-40)\end{array}$ \\
\hline A1 Acceptance & 36 & 36 & 20 & 7 \\
A2 Fear of seizures & 20 & 8 & 57 & 15 \\
A3 Employment & 31 & 28 & 27 & 13 \\
A4 Future & 47 & 24 & 28 & 1 \\
A5 Travel & 71 & 15 & 12 & 2 \\
A6 Social life & 56 & 15 & 20 & 9 \\
A7 Leisure & 57 & 12 & 21 & 10 \\
A8 Outlook on life & 51 & 21 & 20 & 8 \\
A9 Family & 65 & 19 & 14 & 2 \\
A10 Medication & 50 & 19 & 27 & 4 \\
A11 Medical profession & 63 & 16 & 16 & 4 \\
A12 Emotions & 53 & 25 & 19 & 3 \\
A13 Isolation & 68 & 13 & 17 & 2 \\
A14 Lack of energy & 57 & 14 & 18 & 11 \\
\end{tabular}

*Severity of problem assessed by weighted scores (1-10, 11-30, 31-40; see text).
The variables which showed a highly significant relation with the psychosocial effects were the total number of attacks experienced and the recency of the last 'seizure. The number and severity of problems experienced by subjects were significantly greater when the total number of seizures experienced was four or more $(F=12.0 ; \mathrm{p}<0.001)$. Furthermore, the nine subjects who said that there were too many seizures to count recorded the highest level of problems. Subjects having their last seizure within one year of data collection were likely to record significantly higher levels of problems than those having their last seizure over 12 months before $(F=44.58 ; \mathrm{p}<0.001)$.

\section{Discussion}

This study examined the extent of psychosocial disturbance in defined areas present at the onset of epilepsy (within one to three years) in an unselected population based cohort of 192 subjects. Previous research has suggested that most patients with chronic epilepsy have significant psychosocial problems. Although we found a high proportion of patients reporting problems $(91 \% ; 175$ subjects), it was in only four areas that more than $10 \%$ of subjects found severe problems. These were fear of seizures, fear of stigma in employment, adverse effects on leisure, and lack of energy. Thus among new patients with epilepsy, although psychosocial problems were widespread, they were generally mild. This contrasts strongly with the results found in studies of patients with chronic epilepsy. ${ }^{2}$

There was no apparent sex difference associated with the results of psychosocial profile, nor any strong relation with marital state and type of job. It was shown, however, that subjects over 60 had less problem in coming to terms with the epilepsy; this may be because most subjects were retired and not concerned with fear of stigmatisation in employment.

In this cohort the diagnosis by itself did not seem to lead to high levels of maladjustment. This runs contrary to the view, often expressed, that the label epilepsy has a powerful and constant stigmatising effect. ${ }^{9}$ In fact, the most significant factors associated with psychosocial maladjustment were the medical aspects of the condition (that is, recency of the last seizure and total number of seizures experienced). Subjects having their last seizure within one year of data collection were likely to record problems at twice the level of those whose last seizure occurred before that date. Rodin suggested something similar when he pointed out that a "patient's life can assume much more normal channels if the threat of recurring seizures is removed and he is able to enjoy freedom from attacks for at least a year and preferably longer." 10 We suggest that even at the early stages of epilepsy significant problems with adjustment would be occurring throughout the group regardless of medical condition if the label were the most important factor in adjustment. That adjustment is related to frequency of seizures weakens the argument for the label's importance. It is, however, not possible for our study totally to disentangle the label from the medical condition as the label will be more salient and used more frequently in association with those subjects who have more frequent seizures.

Our findings suggest that within a population of people with a recent diagnosis of epilepsy, although psychosocial effects were identified in most subjects, severe problems were restricted to a minority. This contrasts markedly with studies in patients with chronic epilepsy. Even at this stage, however, medical factors (numbers and recency of seizures) are important correlates of psychosocial problems. We plan to reexamine the group in a further five years. This will provide an insight into how the course of epilepsy has 
affected development of psychosocial maladjustment and stigma.

We are grateful to the British Epilepsy Association Research Fund for sponsoring this research and to the National Society for Epilepsy for their assistance in making the research possible. The medical aspects of the national general practice study of epilepsy have been generously supported by Action Research and the Brain Research Trust. We also acknowledge Dr J W Sander and Dr Y M Hart for their assistance.

\footnotetext{
I Levine R, Banks S, Berg B. Psychosocial dimensions of epilepsy: a review of the literature. Epilepsia 1988;29:805-16.

DodrillCB, Breyer DN, Diamond MB, Dubinsky BL, Greary BB. Psychosocial problems among adults with epilepsy. Epilepsia 1989;25:168-75.
}

3 Shorvon SD. The temporal aspects of prognosis in epilepsy. $f$ Neurol Neurosurg Psyckiatry 1984;47:1157-65.

4 Hart YM, Sander JW, Johnson AL, Shorvon SD. National general practice study of epilepsy: recurrence after a first seizure. Lancet 1990;336:1271-4.

5 Sander JW, Hart YM, Johnson AL. Shorvon SD. National general practice study of epilepsy: newly diagnosed epileptic seizures in a general population. Lancet 1990;336:1267-71.

6 Hart YM, Sander JW, Shorvon SD. National general practice study of epilepsy and epileptic seizures: objectives and study methodology of the largest reported prospective cohort study of epilepsy. Neuroepidemiology 1989;8: 221-7.

7 Chaplin JE, Yepez R, Shorvon SD, Floyd M. A quantitative approach to measuring the social effects of epilepsy. Neuroepidemiology 1990;9:151-8. Nunnally JC Psychometric theory. New Delhi: Tat McGaw-Hill, 1981.

9 Wright GN. Rehabilitation and the problem of epilepsy. In: Chigier $E$, right GN. Rehabilitation and the problem of epilepsy. In: Chigier E, New dimensions in rehabilitation. Tel Aviv: Gomeh Scientific, 1978:492-6. 1972;13:121-31.

(Accepted 12 March 1992)

Managing Change in Primary Care

\title{
Learning from the past
}

\author{
Justin Allen, Andrew Wilson
}

This is the second in a series of articles looking at how to manage change in general practice

\section{Countesthorpe, \\ Leicestershire \\ Justin Allen, general \\ practitioner}

Department of General Practice, University of Leicester, Leicester LE2 7LX

Andrew Wilson, senior lecturer

Correspondence to: $\mathrm{Dr}$ Wilson.

Series edited by: Dr M Pringle.

BMF 1992;304: 1418-20
Doctors in a three partner practice do all their own on call out of hours work in an equal rota of nights and weekends. The senior partner is aged 56 . He has given vague hints that he is planning to retire at 60 but has never confirmed this. His two junior partners have been in the practice for three and four years respectively. At a partners' meeting he announces that he is proposing to give up his night work as he is finding this increasingly irksome, and has done it uninterrupted for the previous 27 years. He is proposing that the change should take effect from the beginning of the next quarter, in six weeks' time. His proposal is that the junior partners would take over his responsibility and in return would share all the income received for night visists. Much to his surprise he is met with an angry refusal. Hurt and rejected by this response, he gets angry and threatens to dissolve the partnership and the meeting breaks up in uproar.

Most practices will be able to recall similar examples of proposed change going wrong. But most can also point to changes that have been successfully implemented and found to be beneficial. Change, or the possibility of it, is with us all the time. This ranges from the major externally imposed upheavals that have been a feature of general practice over the past few years to minor adjustments within the practice. All practices, therefore, have a wealth of experience of change. Can they use these experiences to improve their management of change? According to Socrates, experience has taught our best flautists, but it has also taught our worst. The following questions allow a practice to review its changes over recent years.

\section{How much have we changed?}

Has the practice been either too stagnant or too unstable? The degree of change and its frequency should be considered. One major change, such as the breaking up of a partnership, might have prolonged repercussions. However, frequent small changes may also have an impact. In industrial settings frequent environmental changes have been shown to boost productivity (the Hawthorne effect). In contrast, general practitioners often complain about the frequency of minor changes, such as to standard referral forms or protocols for child health surveillance.

Have changes been in response to external events or have they been initiated internally? Changes resulting from a perceived need are clearly more likely to be
- Much can be learnt from practices' experience both of proposed change going wrong and of successful change

- Changes resulting from a perceived need internally are more likely to be welcomed than those imposed from outside

- Practice members will have a wide range of different skills to offer and different attitudes towards change

- There must be a workable structure for decision making and style of management

- The way a change is implemented is important to its success

- The effect of change should be evaluated

welcomed and are less traumatic and frustrating than those imposed from outside. This also applies within an organisation; although some members of a practice might feel in control of internally generated change, this does not necessarily apply to others.

\section{What is our attitude to change?}

It is unlikely that all members of the practice feel the same about the benefit or otherwise of change. In any group some will be good at having new ideas, others at analysing positive and negative features of proposals for change, and others at actually initiating change and making it work. As well as there being such a range of skills, attitudes to change will also differ. Some may be naturally conservative and difficult to persuade that any change is better than the status quo. Others may resist change for more pragmatic reasons and argue that it is not worth the disruption it would cause. At the other end of the spectrum some may enjoy the process of change and respond to problems by suggesting a change to the system rather than by trying to make existing arrangements work.

Such a mixture is beneficial to an organisation-if everyone excelled at new ideas but not at following them through little change would occur and all would be frustrated. The benefit of such a mix of skills and attitudes, however, can be realised only if individuals are aware of their own attributes and those of others. Practices may wish to explore this in a formal way by using recognised psychological tests or informally 